\title{
Neonatal olfactory bulb lesions: Influences on subsequent sexual behavior of male mice
}

\author{
A. J. COOPER \\ The Queen's University, Belfast, Northern Ireland
}

\begin{abstract}
Male mice received bilateral lesions to the olfactory bulbs at $24 \mathrm{~h}$ of age. At 90 days of age, aspects of their sexual behavior toward a receptive female were observed. On all measures, the lesioned animals showed lower levels of sexual behavior than did the controls. Examination of their brains showed that the lesioning had involved, on average, little more than half of the bulbs, although there was considerable variation in lesion size. The brains also exhibited other morphological abnormalities. The testes appeared normal. The results are in accordance with those obtained from lesioning adult mice, although the relationship between lesion size and behavioral deficit seems less clear. The study demonstrates the long-lasting consequences of early olfactory system damage.
\end{abstract}

Several recent studies have shown that the integrity of the olfactory system is important for the survival and growth of neonatal mice and rats. It is apparent that neonatal olfactory bulb lesions result in a failure to suck normally, both in mice (McClelland \& Cowley, 1972) and in rats (Singh \& Tobach, 1975). The failure seems to involve an inability to locate the mother's nipple (Cooper \& Cowley, 1976; Hofer, 1976), rather than stemming from altered responsiveness toward the young on the part of the mother (Cooper \& Cowley, 1976; Singh \& Tobach, 1975). The reduction of absence in sucking, in turn, may relate to the young animal's altered receptivity to maternal pheromones. Such reduced olfactory sensitivity may influence limbic system and hypothalamic development, and should the animal survive, this would lead to radically altered physiological and behavioral patterns in adulthood. McClelland and Cowley (1972) have demonstrated that neonatal female mice receiving laterally or centrally placed lesions to the olfactory bulbs show delayed maturation, and subsequently show a lower incidence of pregnancy than controls.

The results of olfactory bulb lesions in adulthood have been explored in a large number of studies. Rowe and Edwards (1972) have shown that in male mice, bulbectomy eliminates sexual behavior, and they interpret this finding in terms of a lack of input from the olfactory areas to the hypothalamus. The finding of Rowe and Smith (1972) that zinc sulphate anosmia does not impair the male's sexual behavior supports the view that in the mouse, the loss of sexual behavior following bulbectomy does not result merely from the sensory defect, but from disruption of limbic mechanisms, with which the olfactory system is in close connection.

The author's present address is Department of Psychology, Miami University, Oxford, Ohio 45056.
If the early olfactory experience of the animal contributes to the limbic organization, then there is reason to expect that early bulb lesions might lead to more generalized and severe behavioral defects than those which follow such lesions in adulthood. The neonate has no previous experience to attenuate the consequences of the defect, nor can it compensate for the loss, for the first 2 weeks of life, with the visual or auditory senses. Its behavioral development will be seriously disturbed, and the effects may be long lasting. The present study is an investigation of the effects of olfactory bulb lesions at $24 \mathrm{~h}$ of age on the subsequent sexual behavior of male mice.

\section{METHOD}

Twenty-six male mice of the outbred CS1 strain were used in this experiment. They were divided into three groups. Group A $(N=8)$ received bilateral lesions to the olfactory bulbs at $24 \mathrm{~h}$, Group B $(\mathrm{N}=9)$ received a control operation at the same age (involving penetration of the skull over the bulbs, without aspiration of tissue), and Group $C(N=9)$ received no surgical treatment. Details of the operative procedure are given in a previous paper (Cooper \& Cowley, 1976). The animals were reared in all-male litters of four pups per litter until weaning at 28 days of age. They were then individually housed in plastic cages, peat moss was provided for bedding, and they were allowed unlimited food and water. Ten days before testing, the mice were moved to the experimental room, which was maintained on a reversed light cycle $(0900-2100 \mathrm{~h}$ dark $)$. Temperature was maintained at around $21^{\circ} \mathrm{C}$. At time of testing, the mice were approximately 90 days old.

Forty female mice were used in the experiment. These were of the same strain (CS1) and similar age as the males, and each had successfully reared either one or two litters. The females were housed in two large cages, 20 to each cage, in the experimental room, 10 days before testing. Within each cage an adult male (nonexperimental) of the CS1 strain was confined in a smaller cage to facilitate regular estrous cycling (Whitten, 1956).

A plastic animal cage $(48 \times 30 \times 18 \mathrm{~cm})$ was used as a testing arena. Its floor was covered by a thin layer of peat moss; a wire 
grill provided a roof. Observations were made during the "lights off' period using a $40-\mathrm{W}$ red light positioned $60 \mathrm{~cm}$ above the arena center.

Testing took place during the afternoon; the male was introduced into the test arena $30 \mathrm{~min}$ before an estrous female (the female's state of estrous was determined by vaginal smear). The behavior of the male toward the female was observed for $20 \mathrm{~min}$. The male was then returned to its cage, and a further vaginal smear was taken from the female (if copulation had occurred) in order to check for spermatozoa. The female was then returned to her cage. Each male received three such trials; a period of 3 days separated each trial. The following measures were taken:

(1) "Sexual interest." A male was scored as exhibiting "sexual interest" in the female if he approached her (other than in what was assessed to be a "casual approach") or if he sniffed at her hindquarters, or followed her around the cage. (2) "Mounting." Each male was scored as either attempting or not attempting to mount the female. (3) "Mount latency." The time elapsing between the introduction of the female and the male's first mounting attempt was recorded. (4) "Mount frequency." The number of times each male mounted the female (with or without intromission) was also recorded. (5) "Intromission." Each male was scored as either achieving intromission with the female or not doing so. Following the three observation periods, each bulbectomized male was housed with a pair of females for 1 week; the females were checked daily for signs of mating.

The males were weighed before and after the experiment. They were then sacrificed and the testes and brains of Groups A and B were removed. The testes were weighed and an estimate made of the extent of bulbectomy, by the method described earlier (Cooper \& Cowley, 1976).

\section{RESULTS}

Where only a probability level is given, this is from the Fisher exact probability test; $t$ values are from the Wilcoxon test; U values are from the Mann-Whitney U test.

\section{Sexual Interest}

Every control operated and unoperated animal showed sexual interest in the female on each of the three trials. During Trial 1, two bulb-lesioned mice did so (A/B, $\mathrm{p}<.005 ; \mathrm{A} / \mathrm{C}, \mathrm{p}<.005)$; on the second trial, three exhibited sexual interest $(\mathrm{A} / \mathrm{B}, \mathrm{p}<.025 ; \mathrm{A} / \mathrm{C}$, $\mathrm{p}<.025)$; and on the third trial, two exhibited sexual interest $(\mathrm{A} / \mathrm{B}, \mathrm{p}<.005 ; \mathrm{A} / \mathrm{C}, \mathrm{p}<.005)$. Even when they were scored as exhibiting sexual interest, the operated animals did so only fleetingly. Only one of them showed interest in the female for longer than $30 \mathrm{sec}$ in any trial. Generally, they seemed not to notice her.

\section{Mounting}

Each control operated and unoperated animal attempted to mount the female in every trial, and this again contrasted with the lesioned mice. Of these, two mounted during Trial 1 (A/B, p <.005; A/C, p <.005), three mounted in Trial $2(\mathrm{~A} / \mathrm{B}, \mathrm{p}<.025 ; \mathrm{A} / \mathrm{C}$, $\mathrm{p}<.025)$, and one mounted in Trial $3(\mathrm{~A} / \mathrm{B}, \mathrm{p}<.005$; $\mathrm{A} / \mathrm{C}, \mathrm{p}<.005)$. In both "sexual interest" and "mounting" categories, it was not the same mice of the lesioned group that showed the behavior in all trials.

\section{Mounting Latency}

Too few lesioned animals attempted mounting to allow statistical analysis, but Table 1 shows the mount latencies of the control operated and unoperated animals. Latencies were lower in Trials 2 and 3 than in Trial 1 in both cases (Wilcoxon $\mathrm{t}=0, \mathrm{p}<.01$, in both groups).

\section{Mount Frequency}

Those lesioned animals that did mount the female did so very infrequently compared to the mice of other groups. Table 1 shows the frequency of mounting for each group on all trials.

\section{Intromission}

The lesioned mice were markedly inferior to the other groups on this measure. None achieved intromission in Trial 1 and only one animal did so in Trials 2 and 3. Over the three trials, the numbers for the control operated mice were 6,5 , and 7 ; for the unoperated, 7, 7, and 6 (Trial 1: A/B, p $<.025 ; \mathrm{A} / \mathrm{C}, \mathrm{p}<.01$; Trial 2: A/B, $\mathrm{p}>.05$, n.s.; A/C, $\mathrm{p}<.025 ;$ Trial 3: $\mathrm{A} / \mathrm{B}, \mathrm{p}<.025 ; \mathrm{A} / \mathrm{C}, \mathrm{p}<.025)$. During the week in which the lesioned mice were housed with the females, no evidence of copulation was found.

One of the lesioned mice died a few days after the completion of the experiment, having lost weight during the 3 days before death. None of the other mice, of any sample, showed any significant weight change during the experiment. The lesioned mice,

Table 1

Sexual Behavior in Neonatally Bulbectomized (Group A), Control Operated (Group B), and Control Unoperated (Group C) Rats

\begin{tabular}{|c|c|c|c|c|c|c|c|c|c|c|c|c|c|c|}
\hline \multirow[b]{3}{*}{ Group } & \multicolumn{3}{|c|}{$\begin{array}{l}\text { Number Showing } \\
\text { Sexual Interest }\end{array}$} & \multicolumn{3}{|c|}{$\begin{array}{l}\text { Number } \\
\text { Mounting }\end{array}$} & \multicolumn{3}{|c|}{$\begin{array}{l}\text { Mount Latency } \\
\text { (Seconds) }\end{array}$} & \multicolumn{3}{|c|}{$\begin{array}{c}\text { Mount } \\
\text { Frequency }\end{array}$} & \multicolumn{2}{|c|}{ Day 110} \\
\hline & \multicolumn{3}{|c|}{ Trial } & \multicolumn{3}{|c|}{ Trial } & \multicolumn{3}{|c|}{ Trial } & \multicolumn{3}{|c|}{ Trial } & \multirow{2}{*}{$\begin{array}{c}\text { MW } \\
\text { (Grams) } \\
\end{array}$} & \multirow{2}{*}{$\begin{array}{c}\mathrm{MW}_{\mathbf{t}} \\
\text { (Grams) }\end{array}$} \\
\hline & 1 & 2 & 3 & 1 & 2 & 3 & 1 & 2 & 3 & 1 & 2 & 3 & & \\
\hline A & 2 & 3 & 2 & 2 & 3 & 1 & & & & 1.5 & 5.0 & 7.0 & 36.2 & .102 \\
\hline B & 9 & 9 & 9 & 9 & 9 & 9 & 376 & 111 & 119 & 19.6 & 22.4 & 20.8 & 43.8 & .139 \\
\hline $\mathrm{C}$ & 9 & 9 & 9 & 9 & 9 & 9 & 345 & 121 & 108 & 22.1 & 21.6 & 20.3 & 44.4 & \\
\hline
\end{tabular}

Note-MW = mean weight on Day 110; $M W_{t}=$ mean weight of testes on Day 110. For Group $A, N=8 ;$ for Groups $B$ and $C, N=9$. 
however, weighed less than the control operated or unoperated mice. Table 1 shows the mean weights of the three groups at time of death, and also the mean weight of the testes of the control operated and bulbectomized mice.

Although the difference was nonsignificant, the testes of the control operated mice were found to be heavier than those of the lesioned mice. This may merely reflect the greater body weight of the former.

\section{Histology}

Macroscopic examination of the brains of Group A mice showed that the mean size of lesion incurred by these animals was $57 \%$ (range, 23\%-83\%). In most cases damage was of equal extent on both sides and involved the anterior parts of the bulbs.

The brains of the lesioned mice appeared abnormal apart from the damaged bulb area. In some cases the symmetry of the brain seemed disturbed, in others glial outgrowths had extended anteriorly from the hemispheres into the area formerly occupied by the bulbs. It is likely that these abnormalities were products of a lesion-induced teratological process, rather than being artifacts of dissection or fixing. None of the control operated group showed the abnormality and, subsequently, I have been unable to reproduce such distortions in normal brains, even after (deliberately) clumsy dissection and long periods of fixing.

Figure 1 shows the dorsal view of the brain of an animal that had lost an estimated $47 \%$ of the bulbs. Asymmetry of the hemispheres is visible; the posterior margin of the left bulb is positioned several millimeters anterior to that of the right bulb. The animal showed no sexual behavior on any trial. One mouse was found to have incurred only slight damage to one bulb (23\% bulbectomy). It mounted the female on two of the three trials.

Histological examination revealed no differences between the testes of bulbectomized mice and controls. In both cases spermatozoa were visible.

\section{DISCUSSION}

The present study provides evidence that olfactory bulb lesions at $24 \mathrm{~h}$ of age severely impair the later sexual behavior of male mice. It supports the finding of Rowe and Edwards (1972) with animals bulbectomized in adulthood. The pattern of sexual deficit is not confined to copulatory performance (activities such as mounting or mating), but often includes a lack of interest in the female (i.e., an absence of following or sniffing at her).

The relationship between the extent of lesion and impairment of behavior is not straightforward. Rowe and Edwards (1972) reported that lesions to adult mice involving removal of $66 \%$ of the bulbs always abolished sexual behavior, whereas in the present study one animal showed some evidence of sexual behavior after incurring removal of $83 \%$ of its bulbs. Conversely, one animal showed no sexual behavior after the removal of $47 \%$ of its bulbs, and another only transient interest on one trial after removal of $34 \%$ of the bulbs.

In the present study, the olfactory acuity of the mice

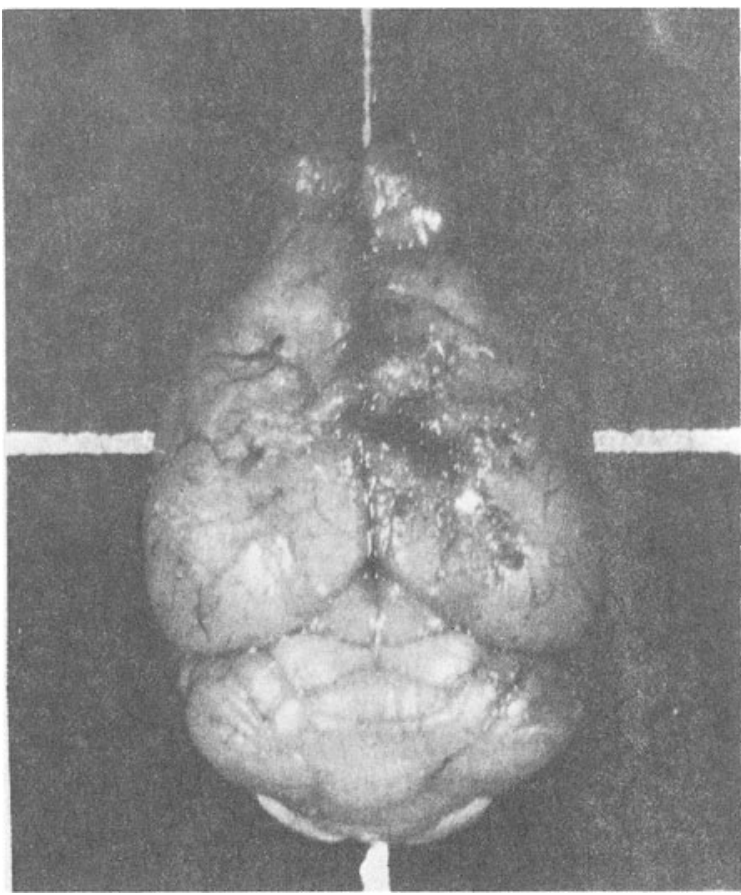

Figure 1. Brain with $47 \%$ bulb removal. The cerebral hemispheres appear asymmetrical. The animal showed no sexual behavior.

was not tested. However, using a similar group of neonatally bulbectomized mice, impaired acuity has been found in adulthood (using a food-location test), and a significant relationship has been found between lesion size and olfactory impairment (Cooper \& Crowley, Note 1). It seems probable, therefore, that as a group the bulbectomized mice in the current study had impaired olfactory ability, but that this impairment was not total, at least in the case of the less extensively lesioned mice. This would provide further evidence that the impairment in sexual behavior is not caused only by the olfactory deficit, but is part of a more general defect, to which some degree of sensory loss has been a contributory factor. Evidence exists to show that lesions placed in infancy may result in more serious defects than those placed in adulthood. Bermant and Taylor (1969) report only partial impairment of sexual behavior in male rats bulbectomized as adults, whereas Kling (1964) has reported that males undergoing transection of the olfactory stalk during the preweaning period do not mate as adults. Johnson (1972) has argued that early lesioning to brain areas other than the neocortex may lead to irreversible changes in basic species-specific behaviors, and so if olfactory information contributes to the development of these behaviors, long-lasting deficits would be expected to occur. Additionally, the morphological abnormalities characterizing the brains of lesioned mice are suggestive of altered function. Hayes (1967) has shown that specific early lesions lead to abnormal development of the rat's brain, and to altered "intelligence."

In the present study, the short period of testing $(20 \mathrm{~min}$ for each trial) was insufficient to allow many of the control operated or unoperated animals to complete the copulation and ejaculate. During this time, most of the lesioned mice showed no sexual behavior at all, but the possibility remains that, had the observation period been lengthened sufficiently, these animals would have shown sexual behavior. As the subsequent week of testing merely involved checking the females for vaginal plugs (of which none was detected), the possibility 
that these animals might exhibit some high-latency, incomplete sexual behavior cannot be excluded.

These results show that early, subtotal lesions to the olfactory bulbs of male mice result in diminished sexual behavior when the animals are tested as adults. There is evidence that similar lesions impair subsequent discrimination learning (Cooper \& Cowley, Note 1), and it is likely that these deficits reflect a syndrome characterized by changed reactivity and emotionality. Sexual activity, as a component of the animals' social behavior, is disrupted as a consequence of these changes.

\section{REFERENCE NOTE}

1. Cooper, A. J., \& Cowley, J. J. Effects of neonatal bulbectomy on later discrimination learning in mice, in preparation.

\section{REFERENCES}

Bermant, G., \& TAYLOR, L. Interactive effects of experience and olfactory bulb lesions in male rat copulation. Physiology and Behavior, 1969, 4, 13-17.

COOPER, A. J., \& Cowley, J. J. Mother-infant interaction in mice bulbectomised early in life. Physiology and Behavior, 1976, 16, 453-459.

HAYES, K. J. Neonatal brain lesions and intelligence in rats. Psychonomic Science, 1967, 9, 279-280.
Hofer, M. H. Olfactory denervation: Its biological and behavioral effects in infant rats. Journal of Comparative and Physiological Psychology, 1976, 78, 829-839.

Johnson, D. A. Developmental aspects of recovery of function following septal lesions in the infant rat. Journal of Comparative and Physiological Psychology, 1972, 78, 331-338.

KLING, A. Effects of rhinencephalic lesions on endocrine and somatic development in the rat. American Journal of Physiology, 1964, 206, 1395-1400.

McClelland, R. J., \& Cowley, J. J. The effects of lesions of the olfactory bulbs on the growth and behavior of mice. Physiology and Behavior, 1972, 9, 319-324.

Rowe, F. A., \& EDwards, D. A. Olfactory bulb removal: Influences on the mating behavior of male mice. Physiology and Behavior, 1972, 8, 37-41.

Rowe, F. A., \& SмITH, W. E. Effects of peripherally induced anosmia on mating behavior of male mice. Psychonomic Science, 1972, 27, 33-34.

Singh, P. J., \& Tовасн, E. Olfactory bulbectomy and nursing behavior in rat pups (Wistar D.A.B.). Developmental Psychobiology, 1975, 8, 151-164.

Whitten, W. K. Modification of the oestrous cycle of the mouse by external stimuli associated with the male. Journal of Endocrinology, 1956, 13, 399-404.

(Received for publication October 18, 1977.) 